Published in final edited form as:

Clin Cancer Res. 2021 May 01; 27(9): 2408-2415. doi:10.1158/1078-0432.CCR-20-3854.

\title{
Modernizing Clinical Trial Eligibility Criteria: Recommendations of the ASCO-Friends of Cancer Research Prior Therapies Work Group
}

\author{
Raymond U. Osarogiagbon ${ }^{1}$, Diana Merino Vega ${ }^{2}$, Lola Fashoyin-Aje ${ }^{3}$, Suparna Wedam ${ }^{3}$, \\ Gwynn Ison ${ }^{3}$, Sol Atienza ${ }^{4}$, Peter De Porre ${ }^{5}$, Tithi Biswas ${ }^{6}$, Jamie N Holloway ${ }^{7}$, David S \\ Hong $^{8}$, Madison M Wempe ${ }^{2}$, Richard L. Schilsky ${ }^{9}$, Edward S. Kim ${ }^{10}$, James L Wade IIII1 \\ ${ }^{1}$ Multidisciplinary Thoracic Oncology Program, Baptist Cancer Center, Memphis, TN, USA \\ ${ }^{2}$ Friends of Cancer Research, Washington, DC, USA \\ ${ }^{3}$ U.S. Food and Drug Administration, Silver Spring, MD, USA \\ ${ }^{4}$ Advocate Aurora Health, Milwaukee, WI, USA \\ 5Janssen Pharmaceutica, Beerse, Belgium \\ ${ }^{6}$ University Hospitals Seidman Cancer Center, Cleveland, OH, USA \\ ${ }^{7}$ Patient Advocate, Arlington, VA, USA \\ ${ }^{8}$ MD Anderson Cancer Center, Houston, TX, USA \\ ${ }^{9}$ American Society of Clinical Oncology, Alexandria, VA, USA \\ ${ }^{10}$ Levine Cancer Institute, Atrium Health, Charlotte, NC, USA \\ ${ }^{11}$ Cancer Care Specialists of Central Illinois, Decatur, IL, USA
}

\begin{abstract}
Purpose: Restrictive eligibility criteria induce differences between clinical trial and 'real-world' treatment populations. Restrictions based on prior therapies are common; minimizing them when appropriate may increase patient participation in clinical trials.
\end{abstract}

\footnotetext{
*Corresponding Author: Raymond U. Osarogiagbon, Baptist Cancer Center - Memphis, 80 Humphreys Center Dr, Ste 3320, Memphis, TN 38120 USA, Raymond.Osarogiagbon@bmg.md, Phone: (901) 722-0540.

Related Manuscripts

This manuscript is submitted as part of a six manuscript bundle. The five related manuscripts listed below are attached.

Harvey et al., "Impact of Broadening Trial Eligibility Criteria for Advanced Non-Small Cell Lung Cancer (NSCLC) Patients: RealWorld Analysis of Select ASCO-Friends Recommendations"

Harvey et al., "Modernizing Clinical Trial Eligibility Criteria: Recommendations of the ASCO-Friends of Cancer Research Washout Period and Concomitant Medication Work Group"

Kim et al., "Continuing to Broaden Eligibility Criteria to Make Clinical Trials More Representative and Inclusive: ASCO-Friends of Cancer Research Joint Research Statement"

Magnuson et al., "Modernizing Clinical Trial Eligibility Criteria: Recommendations of the ASCO-Friends of Cancer Research Performance Status Work Group"

Spira et al., "Modernizing Clinical Trial Eligibility Criteria: Recommendations of the ASCO-Friends of Cancer Research Laboratory Reference Ranges and Testing Intervals Work Group" DISCLAIMER:

The opinions expressed in this article are those of the authors and do not necessarily reflect the views or policies of the authors' affiliated institutions.
} 
Methods: A multi-stakeholder working group developed a conceptual framework to guide evaluation of prevailing practices with respect to using prior treatment as selection criteria for clinical trials. The working group made recommendations to minimize restrictions based on prior therapies within the boundaries of scientific validity, patient-centeredness, distributive justice and beneficence.

Recommendations: 1) Patients are eligible for clinical trials regardless of the number or type of prior therapies and without requiring a specific therapy prior to enrollment unless a scientific or clinically-based rationale is provided as justification. 2) Prior therapy (either limits on number and type of prior therapies or requirements for specific therapies before enrollment) could be used to determine eligibility in the following cases: a) the agents being studied target a specific mechanism or pathway that could potentially interact with a prior therapy; b) the study design requires that all patients begin protocol-specified treatment at the same point in the disease trajectory; c) in randomized clinical studies, if the therapy in the control arm is not appropriate for the patient due to previous therapies received. 3) Trial designers should consider conducting evaluation separately from the primary endpoint analysis for participants who have received prior therapies.

Conclusion: Clinical trial sponsors and regulators should thoughtfully re-examine the use of prior therapy exposure as selection criteria to maximize clinical trial participation.

\section{Keywords}

Clinical trials; access; equity; generalizability

\section{INTRODUCTION}

An expanding number of innovative approaches to cancer treatment, such as targeted anticancer therapies, are reframing our approach to patient selection for the evaluation of experimental agents in clinical trials.(1) For example, targeted anti-cancer therapies are efficacious in molecularly defined patient subsets, irrespective of previous exposure to other types of treatment; they also tend to have more favorable side-effect profiles than traditional cytotoxic chemotherapeutic agents, thus patients treated with targeted agents are often physically well enough to receive subsequent therapies.(2-8) With ever-increasing understanding of drug interactions and novel toxicity profiles of innovative therapies, it is important to rethink the use of prior therapy as eligibility criteria for patient exclusion or inclusion into controlled studies.

The prior therapy selection criteria are a key aspect of clinical trial design and vary substantially, depending on the goals of the study. Updating their use would promote patient access to experimental drugs, improve patient participation, clinical trials accrual and increase the applicability of trial results to a more general population of patients. The rationale for broadening eligibility criteria to make clinical trial participants more representative of the general population has been previously described in a joint effort by the American Society of Clinical Oncology (ASCO) and Friends of Cancer Research (Friends).

(9) Key recommendations to modernize clinical trial eligibility criteria associated with minimum age,(10) organ dysfunction, prior or concurrent malignancies,(11) brain 
metastases,(12) and HIV infection(13) have been published and led to new guidance documents development by the U.S. Food and Drug Administration (14-17).

Building on the success of this initial effort, ASCO and Friends convened a multistakeholder working group of experts from multiple disciplines to evaluate the current practice of using prior therapy as entry criteria for clinical trials, and developed recommendations to support the design and conduct of clinical trials.

\section{PROCESS}

The ASCO-Friends Prior Therapies Working Group included clinical investigators, clinical pharmacologists, patient advocates, and regulatory and industry representatives. The working group developed a framework for eliminating barriers to participation in clinical trials based on restrictive criteria on the types and timing of prior cancer therapy, in order to maximize inclusivity in clinical trials. All working group members acknowledged that the use of prior therapies as a criterion for eligibility is deeply tied to clinical trial design. For example, a trial may require patients to be treatment-naïve if investigating an agent as frontline therapy, while another trial may require patients to have received a specific prior therapy or a limited number of prior therapies if investigating an agent as a later line of therapy, or if a prior therapy is known to interact with the investigational agent.

The working group, thus, developed a conceptual framework with which to guide subsequent discussions; and reviewed a sample of the most recently registered, ongoing clinical trials in five disease areas selected from the ClinicalTrials.gov website to examine how prior therapies are being used as eligibility criteria. The working group used these insights to guide subsequent discussions that led to the final proposed recommendations.

\section{Conceptual Framework}

We developed a conceptual framework for evaluating the advantages and limitations of using prior therapy as eligibility criteria in clinical trials (Figure 1). This framework considers both information about the potential or known toxicity of the experimental agent and its efficacy in relation to existing treatments, to determine the appropriateness of restricting clinical trial participation based on previous treatments. By deconstructing the decision-making process into its basic elements of safety and efficacy, the working group was able to develop recommendations within the context of patient-centeredness, keeping with the ethical principles of distributive justice and beneficence. $(18,19)$ These considerations guided the thought process behind the ClinicalTrials.gov exercise and the recommendations proposed by this working group.

\section{Current Use of Prior Therapies as Eligibility Criteria- ClinicalTrials.gov Assessment}

In order to better understand the scope of the problem, we used the ClinicalTrials.gov website to assess the extent to which prior therapy is currently used as eligibility criteria.(20) In July 2019, we accessed the ClinicalTrials.gov website to select the 11-12 most recently registered phase I-III clinical trials in breast cancer, colon cancer, lung cancer, malignant melanoma and multiple myeloma, for close evaluation of how prior therapy requirements were being used as eligibility criteria. The working group defined inclusion and exclusion 
criteria based on prior therapies as those criteria that did not have a specified washout period. Any criteria based on prior therapies that included a washout period were categorized as "washout period criteria" and not assessed in this study. Trials were categorized by cancer type, clinical trial phase (with Phase I/Phase II trials considered Phase I due to their emphasis on the exploration of safety endpoints), and by drug class (including immunotherapy - alone or in combination, chemotherapy only, and other).

The working group reviewed a total of 57 trials to assess whether there were requirements based on prior therapies, specifying whether these were inclusion or exclusion criteria (Figure 2, Supplemental Table 1). Thirty-three clinical trials corresponded to phase I (58\%), fifteen trials to phase II (26\%) and nine to phase III (16\%). More than ninety percent of clinical trials investigated immunotherapies $(91 \%, 52 / 57)$, either alone or in combination with other agents or treatment modalities, such as chemotherapy and radiotherapy. Of the remaining five clinical trials (9\%), 4 investigated other therapies, such as retinoid $\mathrm{X}$ receptor and hyperbaric oxygen, and 1 investigated a chemotherapy agent only (Supplemental Table 1). The breakdown of clinical trials by cancer type was 12 trials in breast cancer, 11 in colon cancer, 11 in lung cancer, 11 in melanoma and 12 in multiple myeloma.

Two thirds (38/57) of the trials included prior therapy as an eligibility criterion; 19 trials (33\%) did not specify prior therapy as an eligibility criterion. Among 38 trials, 19 (50\%) specified prior therapy as an exclusion criterion only, 14 (37\%) specified prior therapy as both an inclusion and exclusion criterion, and $5(13 \%)$ specified prior therapy as an inclusion criterion only. When categorized by clinical trial phase, 58\% (19/33) of phase I trials specified either an inclusion or exclusion criterion based on prior therapies, while $42 \%$ (14/33) did not. Of the 15 phase II trials, 10 (67\%) specified either an inclusion or exclusion criterion based on prior therapies, compared to 5 (33\%), which did not. Lastly, all 9 phase III trials specified either an inclusion or exclusion criterion based on prior therapies, with exclusion criterion only specified in 6 trials $(67 \%)$, and both inclusion and exclusion criteria based on prior therapies specified in 3 trials (33\%) (Figure 2).

The pattern of use of prior therapies as eligibility criteria in trials categorized by drug class and tumor type is shown in Figure 2. Use was most prevalent in lung cancer trials ( $82 \%$, $9 / 11)$ and least prevalent in melanoma trials $(45 \%, 5 / 11)$. The predominance of immunotherapy trials in the survey, which may be indicative of the predominance of immunotherapy trials in recent ClinicalTrials.gov registrations, may limit the extrapolation of our findings to non-immunotherapy trials.

\section{RECOMMENDATIONS}

Taking all available evidence into consideration, the working group proposed the recommendations outlined in Table 1, based on the key principles of preserving patient safety, facilitating the assessment of drug efficacy, and promoting patient-centeredness. The recommendations reflect the general position that as a default, minimal eligibility restrictions based on prior therapy should be implemented. The working group encourages critical thinking about the appropriate use of eligibility criteria based on prior therapies by 
considering the need to balance the goals of scientific rigor, and trial efficiency, with the goal of broader clinical trial inclusivity.

\section{DISCUSSION}

Traditionally, clinical trials specify prior therapies that are either required for inclusion or exclusion of patients from participation. Tightly controlled eligibility criteria are thought to optimize conditions to test the safety and efficacy of an investigational therapy. $(21,22)$ The working group characterized scenarios under which the use of prior therapies as exclusion criteria (i.e., no prior therapy or no prior therapy of a certain type allowed) or as inclusion criteria (i.e., a defined number and/or type of prior therapies required for eligibility), may be appropriate. We further outlined the rationale for, and the pros and cons of, these scenarios (Table 2). We avoided scenarios in which prior therapies might be specified to exclude overlapping exposure to prior and new therapy (i.e., washout periods), deferring to the ASCO-Friends working group on Washout Periods and Concomitant Medications, which was charged with the task of addressing this important topic ().

For example, to 'optimize for safety' prevailing practice may be to specify a maximum number of prior therapy exposures, in order to minimize the risk that heavily pre-treated patients may be more likely to experience excessive toxicity. Another common practice may be to limit prior exposure to specific types of prior therapies whose toxicities potentially overlap those of the experimental therapy, such as would be the case for potentially irreversible toxicities like bone marrow toxicity, neuropathy, or cardiotoxicity. However, the concerns for excess toxicity may be more appropriately addressed by requiring resolution or improvement in the toxicities of concern, rather than by implementing broad exclusions based upon exposure to prior therapies.

Eligibility criteria may also be designed to 'optimize for efficacy' by defining a study population that is comparable to historical trials to permit an evaluation of improvements in outcomes with the new therapeutic in non-comparative trials. Trial designers may seek to define a study population that is most likely to respond to the treatment being studied. For example positioning a second-generation agent targeting resistance mutations where either relapse after a first-generation compound has selected for the acquired resistance mutation or designing upfront treatment for an ab origin mutation, $(23,24)$ or limiting the number of prior treatments to minimize the risk that heavily pre-treated patients with refractory disease will bias trial results against treatment response. $(25,26)$ This raises the fundamental question whether restricting patients from enrollment in a clinical trial solely based on prior therapy is justifiable to show the best outcome of the trial treatment for a specified patient population or whether it is more advantageous to open up patient eligibility in order to enable quantification of outcomes across the spectrum of potential clinical use scenarios. $(22,27)$

In addition to safety and efficacy considerations, the intent of the trial is an important consideration. A trial designed to evaluate safety and effectiveness of an investigational agent for the purposes of gaining marketing licensure may seek to enroll patients with an unmet medical need, for example patients with advanced refractory disease who have exhausted currently available treatment options, for whom clinical trials may be the only 
potential treatment option. $(28,29)$ A trial may be designed to compare a new investigational agent against a standard of care treatment in a particular treatment setting, such as a specific line of therapy or treatment with a particular class of drugs.(30,31) In this case, trial designers often insist that a study population be naïve to any treatment or restricted to a population that has received a minimum or maximum number, or certain specific types, of prior therapies.

Advances in the understanding of the biological underpinnings of cancer have facilitated the development of therapies that are based on key tumor characteristics such as gene and protein expression profiles, have relatively well-understood mechanisms of action, are often effective irrespective of prior drug exposures, and have a wider therapeutic index.(2-5,3238) This has mostly rendered obsolete the clinical rationale for eligibility criteria that specify requirements for prior therapy, simultaneously raising the ethical dilemma of the opportunity cost to the patient, of arbitrary patient selection criteria based on prior therapy. $(18,19,39)$ Patients increasingly seek access to promising drugs in development, particularly those that treat rare or clinically aggressive cancers. Mandating prior exposure to marginally effective or excessively toxic treatments, in theory, may delay or prevent access to potentially more beneficial novel treatment. Conversely, blanket exclusion of patients who have received any prior treatment may prevent otherwise healthy patients with disease progression from gaining access to potentially health-preserving new treatments.

Lastly, the implementation of prior therapy criteria in the absence of scientific or clinical rationale may unnecessarily restrict the post-approval target population and delay evaluation of a new drug's efficacy and safety in the wider population that may ultimately receive the drug once it is approved.(40) Limiting patient access to clinical trials based either on exposure to prior therapies or the requirement for patients to have progressed after specific therapies limits patient access to clinical trials and may significantly slow trial accrual or compromise completion of these trials.

\section{CONCLUSION}

The discovery of highly effective anti-cancer treatments, and the technologies that enable the selection of patients with targetable genomic alterations, has resulted in the traditional lineof-treatment demarcations becoming increasingly blurred. Ultimately, the inclination to conduct clinical trials in homogeneous populations for more robust comparisons (internal validity) must be finely balanced against the pragmatic need to test novel therapies in the 'real-world' populations that will eventually be exposed to approved treatments (external validity),(40) as well as the concept of patient-centeredness, and the ethical principles of distributive justice and beneficence. The Institute of Medicine, now National Academy of Medicine, defined patient-centeredness as 'responsiveness to the needs, values, and expressed preferences of the individual patient.'(41) In 2010, the same body recommended that the National Cancer Institute, Cooperative Groups and physicians should take steps to increase the speed, volume and diversity of patient accrual and to ensure high-quality performance at all sites participating in cooperative group trials. As an example, they recommended that they should "encourage patient eligibility criteria that allow the broadest participation possible.”(42) 
Clinical trial designers and sponsors should clearly justify any restrictions based on prior therapies. The working group's overarching consideration in making these recommendations was to promote patient-centered clinical trials with the minimum entry criteria needed to ensure participant safety and broad access. We hope these recommendations will be widely adopted by key stakeholders, especially designers, sponsors, and regulators of clinical trials.

\title{
Supplementary Material
}

Refer to Web version on PubMed Central for supplementary material.

\section{ACKNOWLEDGEMENTS:}

\author{
The working group would like to acknowledge Drs. Wayne Rackoff (Janssen) and Lee Krug (Bristol Myers Squibb) \\ for their insightful contribution to the initial development of the concepts discussed in this manuscript. \\ Financial Support \\ Osarogiagbon: supported by NIH 2UG1CA189873-06 \\ Conflict of Interest Disclosure
}

The authors declare no potential conflicts of interest other than those listed below for individual authors:

De Porre: employee of Janssen

Holloway: employee of Caris Life Sciences

Hong:

Research/Grant Funding: AbbVie, Adaptimmune, Aldi-Norte, Amgen, Astra-Zeneca, Bayer, BMS, DaiichiSankyo, Eisai, Fate Therapeutics, Genentech, Genmab, Ignyta, Infinity, Kite, Kyowa, Lilly, LOXO, Merck, MedImmune, Mirati, miRNA, Molecular Templates, Mologen, NCI-CTEP, Novartis, Numab, Pfizer, Seattle Genetics, Takeda, Turning Point Therapeutics, Verstatem

Travel, Accommodations, Expenses: Bayer, LOXO, miRNA, Genmab, AACR, ASCO, SITC

Consulting or Advisory Role: Alpha Insights, Acuta, Amgen, Axiom, Adaptimmune, Baxter, Bayer, Boxer Capital, COG, ECOR1, Expert Connect, Genentech, GLG, Group H, Guidepoint, H.C. Wainwright, Infinity, Janssen, Merrimack, Medscape, NTRK Connect, Numab, Pfizer, Prime Oncology, Seattle Genetics, SlingShot, Takeda, Trieza Therapeutics, WebMD

Other ownership interests: Molecular Match (Advisor), OncoResponse (Founder), Presagia Inc (Advisor)

Osarogiagbon:

Consulting or Advisory Role: American Cancer Society, the Association of Community Cancer Centers, AstraZeneca, Biodesix, Eli Lilly, Triptych Healthcare Partners.

Other ownership interests: patents for the lymph node specimen collection kit; stocks in Eli Lilly, Gilead Sciences, and Pfizer; founder of Oncobox Device, Inc

\section{REFERENCES}

1. Heymach J, Krilov L, Alberg A, Baxter N, Chang SM, Corcoran RB, et al. Clinical Cancer Advances 2018: Annual Report on Progress Against Cancer From the American Society of Clinical Oncology. J Clin Oncol [Internet]. American Society of Clinical Oncology; 2018;36:1020-44. Available from: 10.1200/JCO.2017.77.0446 [PubMed: 29380678]

2. Fontes Jardim DL, Schwaederle M, Wei C, Lee JJ, Hong DS, Eggermont AM, et al. Impact of a Biomarker-Based Strategy on Oncology Drug Development: A Meta-Analysis of Clinical Trials 
Leading to FDA Approval. JNCI J Natl Cancer Inst [Internet]. 2015;107. Available from: 10.1093/ jnci/djv253

3. Zhang S, Anjum R, Squillace R, Nadworny S, Zhou T, Keats J, et al. The Potent ALK Inhibitor Brigatinib (AP26113) Overcomes Mechanisms of Resistance to First- and Second-Generation ALK Inhibitors in Preclinical Models. Clin Cancer Res [Internet]. 2016; Available from: http:// clincancerres.aacrjournals.org/content/early/2016/10/21/1078-0432.CCR-16-0569.abstract

4. Rotow J, Bivona TG. Understanding and targeting resistance mechanisms in NSCLC. Nat Rev Cancer [Internet]. 2017;17:637-58. Available from: 10.1038/nrc.2017.84 [PubMed: 29068003]

5. Recondo G, Facchinetti F, Olaussen KA, Besse B, Friboulet L. Making the first move in EGFRdriven or ALK-driven NSCLC: first-generation or next-generation TKI? Nat Rev Clin Oncol [Internet]. 2018;15:694-708. Available from: 10.1038/s41571-018-0081-4 [PubMed: 30108370]

6. Leonetti A, Facchinetti F, Rossi G, Minari R, Conti A, Friboulet L, et al. BRAF in non-small cell lung cancer (NSCLC): Pickaxing another brick in the wall. Cancer Treat Rev [Internet]. 2018/04/24. Netherlands; 2018;66:82-94. Available from: https://pubmed.ncbi.nlm.nih.gov/29729495 [PubMed: 29729495]

7. Proto C, Ferrara R, Signorelli D, Lo Russo G, Galli G, Imbimbo M, et al. Choosing wisely first line immunotherapy in non-small cell lung cancer (NSCLC): what to add and what to leave out. Cancer Treat Rev [Internet]. 2019;75:39-51. Available from: http://www.sciencedirect.com/science/ article/pii/S0305737219300520 [PubMed: 30954906]

8. Kummar S, Gutierrez M, Doroshow JH, Murgo AJ. Drug development in oncology: Classical cytotoxics and molecularly targeted agents. Br J Clin Pharmacol. 2006;62:15-26. [PubMed: 16842375]

9. Kim ES, Bruinooge SS, Roberts S, Ison G, Lin NU, Gore L, et al. Broadening eligibility criteria to make clinical trials more representative: American society of clinical oncology and friends of cancer research joint research statement. J Clin Oncol. 2017;35:3737-44. [PubMed: 28968170]

10. Gore L, Ivy SP, Balis FM, Rubin E, Thornton K, Donoghue M, et al. Modernizing clinical trial eligibility: Recommendations of the American society of clinical oncology-friends of cancer research minimum age working group. J Clin Oncol. 2017;35:3781-7. [PubMed: 28968169]

11. Lichtman SM, Harvey RD, Damiette Smit MA, Rahman A, Thompson MA, Roach N, et al. Modernizing clinical trial eligibility criteria: Recommendations of the American society of clinical oncology-friends of cancer research organ dysfunction, prior or concurrent malignancy, and comorbidities working group. J Clin Oncol. 2017;35:3753-9. [PubMed: 28968172]

12. Lin NU, Prowell T, Tan AR, Kozak M, Rosen O, Amiri-Kordestani L, et al. Modernizing clinical trial eligibility criteria: Recommendations of the American society of clinical oncology-friends of cancer research brain metastases working group. J Clin Oncol. 2017;35:3760-73. [PubMed: 28968165]

13. Uldrick TS, Ison G, Rudek MA, Noy A, Schwartz K, Bruinooge S, et al. Modernizing clinical trial eligibility criteria: Recommendations of the American society of clinical oncology-friends of cancer research HIV working group. J Clin Oncol. 2017;35:3774-80. [PubMed: 28968173]

14. U.S. Food and Drug Administration. Guidance Document: Cancer Clinical Trial Eligibility Criteria: Brain Metastases [Internet]. 2020. Available from: https://www.fda.gov/media/121317/ download

15. U.S. Food and Drug Administration. Guidance Document: Cancer Clinical Trial Eligibility Criteria: Patients with HIV, Hepatitis B Virus, or Hepatitis C Virus Infections [Internet]. 2020. Available from: https://www.fda.gov/media/121319/download

16. U.S. Food and Drug Administration. Guidance Document: Cancer Clinical Trial Eligibility Criteria: Minimum Age for Pediatric Patients. 2020; Available from: https://www.fda.gov/media/ 121318/download

17. U.S. Food and Drug Administration. Guidance Document: Cancer Clinical Trial Eligibility Criteria: Patients with Organ Dysfunction or Prior or Concurrent Malignancies. 2020; Available from: https://www.fda.gov/media/123745/download

18. Laage T, Loewy JW, Menon S, Miller ER, Pulkstenis E, Kan-Dobrosky N, et al. Ethical Considerations in Adaptive Design Clinical Trials. Ther Innov Regul Sci [Internet]. 2016/09/27. 
Switzerland; 2017;51:190-9. Available from: https://pubmed.ncbi.nlm.nih.gov/30231727 [PubMed: 30231727]

19. Markman M Survival and Participation in a Cancer Clinical Trial: A Provocative Relationship. Oncology [Internet]. 2016/08/25. Switzerland; 2016;91:177-8. Available from: https:// pubmed.ncbi.nlm.nih.gov/27560780 [PubMed: 27560780]

20. U.S. National Library of Medicine. ClinicalTrials.gov [Internet]. [cited 2019 Jul 23]. Available from: clinicaltrials.gov

21. Schilsky RL. End points in cancer clinical trials and the drug approval process. Clin Cancer Res [Internet]. United States; 2002;8:935-8. Available from: https://pubmed.ncbi.nlm.nih.gov/ 11948095

22. Jin S, Pazdur R, Sridhara R. Re-evaluating eligibility criteria for oncology clinical trials: Analysis of investigational new drug applications in 2015. J Clin Oncol. 2017;35:3745-52. [PubMed: 28968168]

23. Mok TS, Wu Y-L, Ahn M-J, Garassino MC, Kim HR, Ramalingam SS, et al. Osimertinib or Platinum-Pemetrexed in EGFR T790M-Positive Lung Cancer. N Engl J Med [Internet]. Massachusetts Medical Society; 2016;376:629-40. Available from: 10.1056/NEJMoa1612674 [PubMed: 27959700]

24. Yang JC-H, Ahn M-J, Kim D-W, Ramalingam SS, Sequist LV, Su W-C, et al. Osimertinib in Pretreated T790M-Positive Advanced Non-Small-Cell Lung Cancer: AURA Study Phase II Extension Component. J Clin Oncol [Internet]. American Society of Clinical Oncology; 2017;35:1288-96. Available from: 10.1200/JCO.2016.70.3223 [PubMed: 28221867]

25. Middleton G, Crack LR, Popat S, Swanton C, Hollingsworth SJ, Buller R, et al. The National Lung Matrix Trial: translating the biology of stratification in advanced non-small-cell lung cancer. Ann Oncol Off J Eur Soc Med Oncol [Internet]. 2015/09/25. Oxford University Press; 2015;26:2464-9. Available from: https://pubmed.ncbi.nlm.nih.gov/26410619

26. Moore KN, Mannel RS. Is the NCI MATCH trial a match for gynecologic oncology? Gynecol Oncol [Internet]. 2015/11/14. United States; 2016;140:161-6. Available from: https:// pubmed.ncbi.nlm.nih.gov/26586415 [PubMed: 26586415]

27. Schilsky RL. Publicly funded clinical trials and the future of cancer care. Oncologist [Internet]. 2013/01/30. AlphaMed Press; 2013;18:232-8. Available from: https://pubmed.ncbi.nlm.nih.gov/ 23363807 [PubMed: 23363807]

28. Gadgeel SM, Gandhi L, Riely GJ, Chiappori AA, West HL, Azada MC, et al. Safety and activity of alectinib against systemic disease and brain metastases in patients with crizotinib-resistant ALKrearranged non-small-cell lung cancer (AF-002JG): results from the dose-finding portion of a phase 1/2 study. Lancet Oncol [Internet]. 2014/08/18. England; 2014;15:1119-28. Available from: https://pubmed.ncbi.nlm.nih.gov/25153538 [PubMed: 25153538]

29. Lin JJ, Zhu VW, Schoenfeld AJ, Yeap BY, Saxena A, Ferris LA, et al. Brigatinib in Patients With Alectinib-Refractory ALK-Positive NSCLC. J Thorac Oncol [Internet]. Elsevier Inc; 2018;13:1530-8. Available from: 10.1016/j.jtho.2018.06.005

30. Soria J-C, Ohe Y, Vansteenkiste J, Reungwetwattana T, Chewaskulyong B, Lee KH, et al. Osimertinib in Untreated EGFR-Mutated Advanced Non-Small-Cell Lung Cancer. N Engl J Med [Internet]. Massachusetts Medical Society; 2017;378:113-25. Available from: 10.1056/ NEJMoa1713137 [PubMed: 29151359]

31. Camidge DR, Kim HR, Ahn M-J, Yang JC-H, Han J-Y, Lee J-S, et al. Brigatinib versus Crizotinib in ALK-Positive Non-Small-Cell Lung Cancer. N Engl J Med [Internet]. Massachusetts Medical Society; 2018;379:2027-39. Available from: 10.1056/NEJMoa1810171 [PubMed: 30280657]

32. Le DT, Uram JN, Wang H, Bartlett BR, Kemberling H, Eyring AD, et al. PD-1 Blockade in Tumors with Mismatch-Repair Deficiency. N Engl J Med [Internet]. 2015;372:2509-20. Available from: http://www.nejm.org/doi/10.1056/NEJMoa1500596 [PubMed: 26028255]

33. Prowell TM, Theoret MR, Pazdur R. Seamless Oncology-Drug Development. N Engl J Med [Internet]. Massachusetts Medical Society; 2016;374:2001-3. Available from: 10.1056/ NEJMp1603747 [PubMed: 27074059]

34. Ding MQ, Chen L, Cooper GF, Young JD, Lu X. Precision Oncology Beyond Targeted Therapy: Combining Omics Data with Machine Learning Matches the Majority of Cancer Cells to Effective 
Therapeutics. Mol Cancer Res [Internet]. 2017;molcanres.0378.2017. Available from: http:// mcr.aacrjournals.org/content/early/2017/11/11/1541-7786.MCR-17-0378.abstract

35. Hobbs BP, Barata PC, Kanjanapan Y, Paller CJ, Perlmutter J, Pond GR, et al. Seamless Designs: Current Practice and Considerations for Early-Phase Drug Development in Oncology. J Natl Cancer Inst [Internet]. Oxford University Press; 2019;111:118-28. Available from: https:// pubmed.ncbi.nlm.nih.gov/30561713 [PubMed: 30561713]

36. Savard M-F, Khan O, Hunt KK, Verma S. Redrawing the Lines: The Next Generation of Treatment in Metastatic Breast Cancer. Am Soc Clin Oncol Educ B [Internet]. American Society of Clinical Oncology; 2019;e8-21. Available from: 10.1200/EDBK_237419

37. Solomon BJ, Besse B, Bauer TM, Felip E, Soo RA, Camidge DR, et al. Lorlatinib in patients with ALK-positive non-small-cell lung cancer: results from a global phase 2 study. Lancet Oncol [Internet]. 2018/11/06. England; 2018;19:1654-67. Available from: https:// pubmed.ncbi.nlm.nih.gov/30413378 [PubMed: 30413378]

38. Drilon A, Laetsch TW, Kummar S, Dubois SG, Lassen UN, Demetri GD, et al. Efficacy of larotrectinib in TRK fusion-positive cancers in adults and children. N Engl J Med. 2018;378:7319. [PubMed: 29466156]

39. Printz C Trial and error. Cancer [Internet]. John Wiley \& Sons, Ltd; 2013;119:471-2. Available from: 10.1002/cncr.27960 [PubMed: 23341304]

40. Masuda N, Ohe Y, Gemma A, Kusumoto M, Yamada I, Ishii T, et al. Safety and effectiveness of alectinib in a real-world surveillance study in patients with ALK-positive non-small-cell lung cancer in Japan. Cancer Sci [Internet]. John Wiley \& Sons, Ltd; 2019;110:1401-7. Available from: 10.1111/cas.13977 [PubMed: 30776174]

41. Chapter 2 'Improving the $21^{\text {st }}$-Century Health Care System' in Crossing the Quality Chasm: A New Health System for the $21^{\text {st }}$ Century. Institute of Medicine. National Academy Press 2001.

42. Mendelsohn J, Moses HL, Nass SJ. A national cancer clinical trials system for the 21 st century: Reinvigorating the NCI Cooperative Group Program. National Academies Press; 2010.

43. Renfro LA, An M-W, Mandrekar SJ. Precision oncology: A new era of cancer clinical trials. Cancer Lett [Internet]. 2016/03/14. 2017;387:121-6. Available from: https:// pubmed.ncbi.nlm.nih.gov/26987624 [PubMed: 26987624] 


\section{STATEMENT OF TRANSLATIONAL RELEVANCE}

With rapid-cycle discovery of new drugs with well-characterized targets and mechanisms of action, the therapeutic index and efficacy of new candidate cancer drugs are significantly better than in the past, reconfiguring the safety and efficacy calculus in using prior therapy exposure to select patients for clinical trials. Concurrently, there is growing awareness that cancer drugs approved in restrictive clinical trials are often used in real world practice for groups of patients ineligible for such trials, even without evidence for their safety or efficacy. Using a patient-centered conceptual model that considers safety, efficacy and the ethical principles of distributive justice and beneficence, a multistakeholder working group has proposed three recommendations to promote more thoughtful consideration of the use of prior therapy as a selection criterion for oncology trials. The overarching objective is to minimize this potential barrier to clinical trials access for willing patients. 


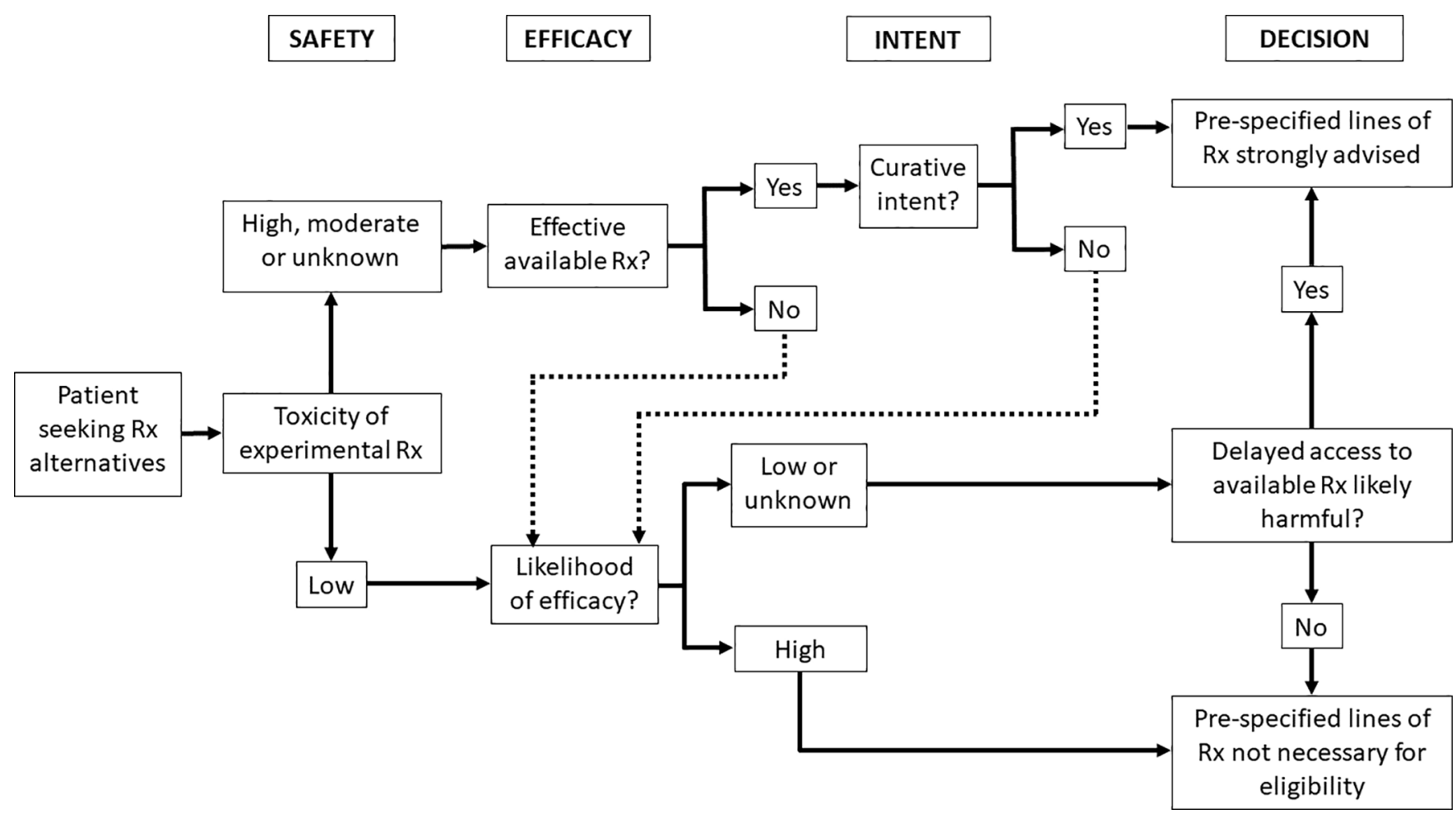

Figure 1. Conceptual framework to guide the use of prior therapy as selection criteria in clinical trials.

We encourage the use of this conceptual framework early in the process of clinical trial design, in order to minimize the barrier to entry. We encourage shared decision-making between the patient and the healthcare provider in selecting treatment options including treatment within a clinical trial. In general, clinical trials should be designed with the aim of achieving greater inclusivity with minimal restrictions placed on trial entry. Decisions regarding whether exposure to existing therapy should be required prior to administering an investigational therapy should consider the risks (i.e., known or unknown safety profile) and the efficacy of the therapy, and the availability of alternative treatments. In a clinical setting wherein the standard of care treatment provides a high likelihood of cure such as may be the case for some in an adjuvant setting or for some advanced lymphomas or pediatric cancers, it may be appropriate to restrict access to experimental therapy until after disease progression, relapse or intolerance of such existing treatments. However, in the non-curative setting a requirement for receipt of such 'standard' options is not recommended unless there is sound scientific or clinical rationale to support the restriction. 


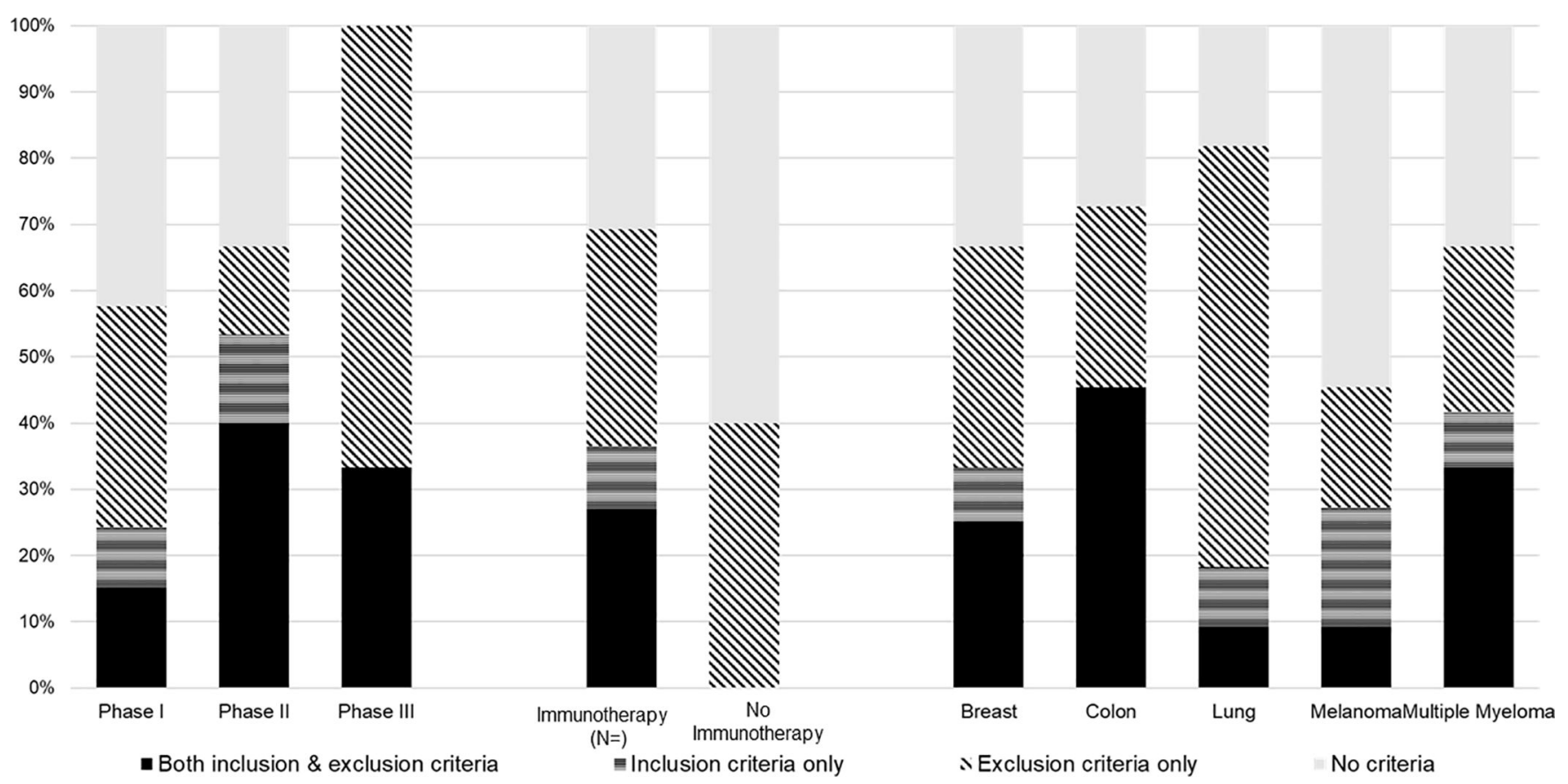

Figure 2. Frequency of the use of prior therapies as inclusion and/or exclusion criteria in clinical trials as part of the ClinicalTrials.gov exercise categorized by phase, drug class and tumor type. ClinicalTrials.gov was accessed on July 23, 2019. Trials with any component of Phase I trials (e.g. Phase I/II) were categorized as Phase I trials. The working group defined inclusion and exclusion criteria based on prior therapies as those criteria that did not have a specified washout period. Any criteria based on prior therapies that included a washout period was categorized as "washout period criteria" and not evaluated in this assessment. 
Table 1.

Recommendations for the modernization of eligibility criteria based on prior therapies

\begin{tabular}{|c|c|}
\hline Recommendation & Comment \\
\hline $\begin{array}{l}\text { 1. Patients are eligible for } \\
\text { clinical trials regardless of the } \\
\text { number or type of prior } \\
\text { therapies and without a } \\
\text { requirement to have received a } \\
\text { specific therapy prior to } \\
\text { enrollment unless a scientific } \\
\text { or clinical rationale is provided } \\
\text { as justification. }\end{array}$ & $\begin{array}{l}\text { There needs to be a balance between the desire to conduct a tightly controlled experiment with high internal } \\
\text { validity, and the reality that patients with much broader demographic and disease characteristics than those } \\
\text { patients evaluated in clinical trials, are prescribed the approved drugs.(22) } \\
\text { Clinical trials are the most controlled mechanism for evaluation of the safety and efficacy of investigational } \\
\text { agents in a carefully selected patient population. However, arbitrary exclusion of populations of patients } \\
\text { who may desire access to clinical trials, and may derive benefit from them, runs counter to the principles of } \\
\text { patient autonomy and beneficence. The opportunity cost of such arbitrary restrictions to sponsors and } \\
\text { designers of clinical trials may also be largely under-recognized. } \\
\text { Overly complex eligibility criteria may in part increase the burden on research staff, slow down clinical trial } \\
\text { accrual, increase the risk of failure to complete clinical trials, and raise the audit and regulatory stakes for } \\
\text { enrolling sites and their staff. Indeed, the Pharmaceutical Research and Manufacturers Association reported } \\
\text { that } 80 \% \text { of clinical trials do not finish on time, } 20 \% \text { are delayed } 6 \text { months or more and up to two-thirds of } \\
\text { clinical trials fail to meet their original patient enrollment goals.(39) Reducing barriers that hinder } \\
\text { recruitment, such as broadening eligibility criteria, would be beneficial. }\end{array}$ \\
\hline $\begin{array}{l}\text { 2. Prior therapy (either limits } \\
\text { on the number and type of } \\
\text { prior therapies or requirements } \\
\text { for specific therapies before } \\
\text { enrollment) could be used to } \\
\text { determine eligibility in the } \\
\text { following cases: }\end{array}$ & \multirow{4}{*}{$\begin{array}{l}\text { To promote greater clinical trial inclusivity in trials, minimally restrictive criteria should be used, with } \\
\text { patient safety and autonomy as the primary considerations. However, there may be some specific scenarios } \\
\text { in which these criteria may be justifiable and necessary to maintain patient safety and ensure treatment } \\
\text { efficacy. In these cases, when entry into a trial is contingent upon exposure to a prior therapy (or lack } \\
\text { thereof), scientific and/or clinically sound rationale should be provided. } \\
\text { The working group identified three cases in which prior therapy could be used to determine patient } \\
\text { eligibility, and additional specific scenarios are found in Table } 2 \text {. } \\
\text { With evolving evidence that investigational agents with known mechanisms of action, which effectively } \\
\text { target specific biologic pathways, are highly effective irrespective of the point in the disease trajectory, (2- } \\
5,32-36,38,43 \text { ) trial designers are encouraged to continuously re-evaluate the use of prior therapies as } \\
\text { eligibility criteria. }\end{array}$} \\
\hline $\begin{array}{l}\text { a. If the agents being studied } \\
\text { target a specific mechanism or } \\
\text { pathway that could potentially } \\
\text { interact with a prior therapy. }\end{array}$ & \\
\hline $\begin{array}{l}\text { b. If the study design } \\
\text { requires that all patients begin } \\
\text { protocol-specified treatment at } \\
\text { the same point in the disease } \\
\text { trajectory. }\end{array}$ & \\
\hline $\begin{array}{l}\text { c. In randomized clinical } \\
\text { studies, if the therapy in the } \\
\text { control arm is not appropriate } \\
\text { for the patient due to previous } \\
\text { therapies received }\end{array}$ & \\
\hline $\begin{array}{l}\text { 3. Trial designers should } \\
\text { consider conducting evaluation } \\
\text { separately from the primary } \\
\text { endpoint analysis for } \\
\text { participants who have received } \\
\text { prior therapies. }\end{array}$ & 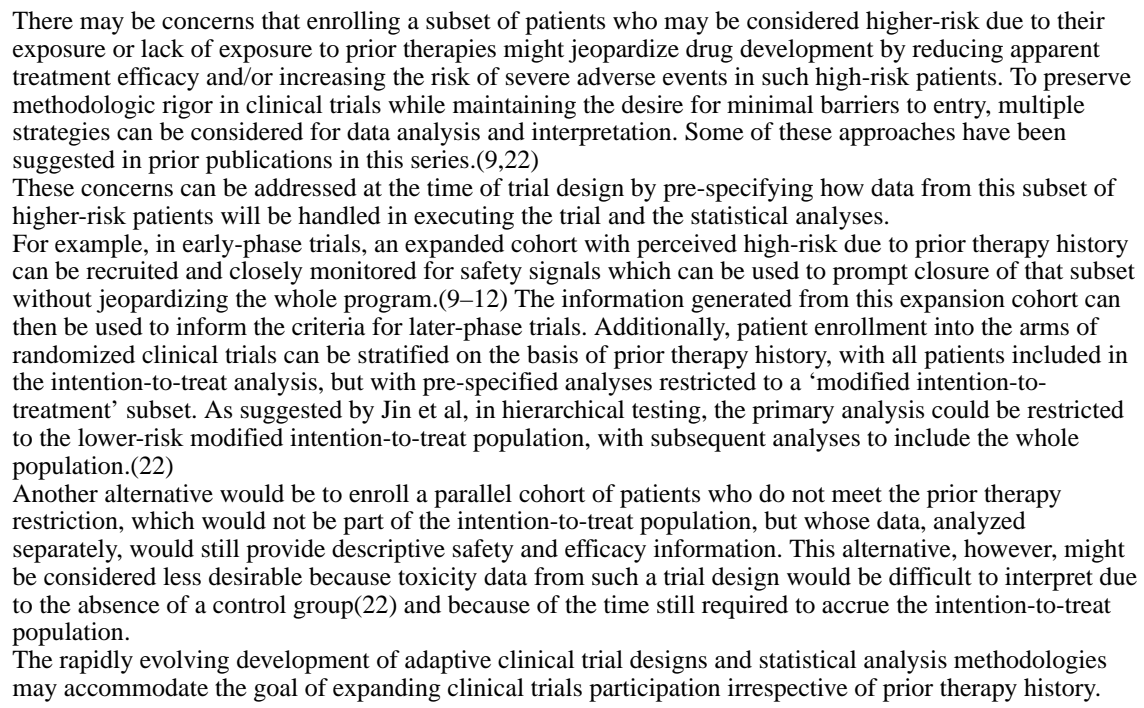 \\
\hline
\end{tabular}




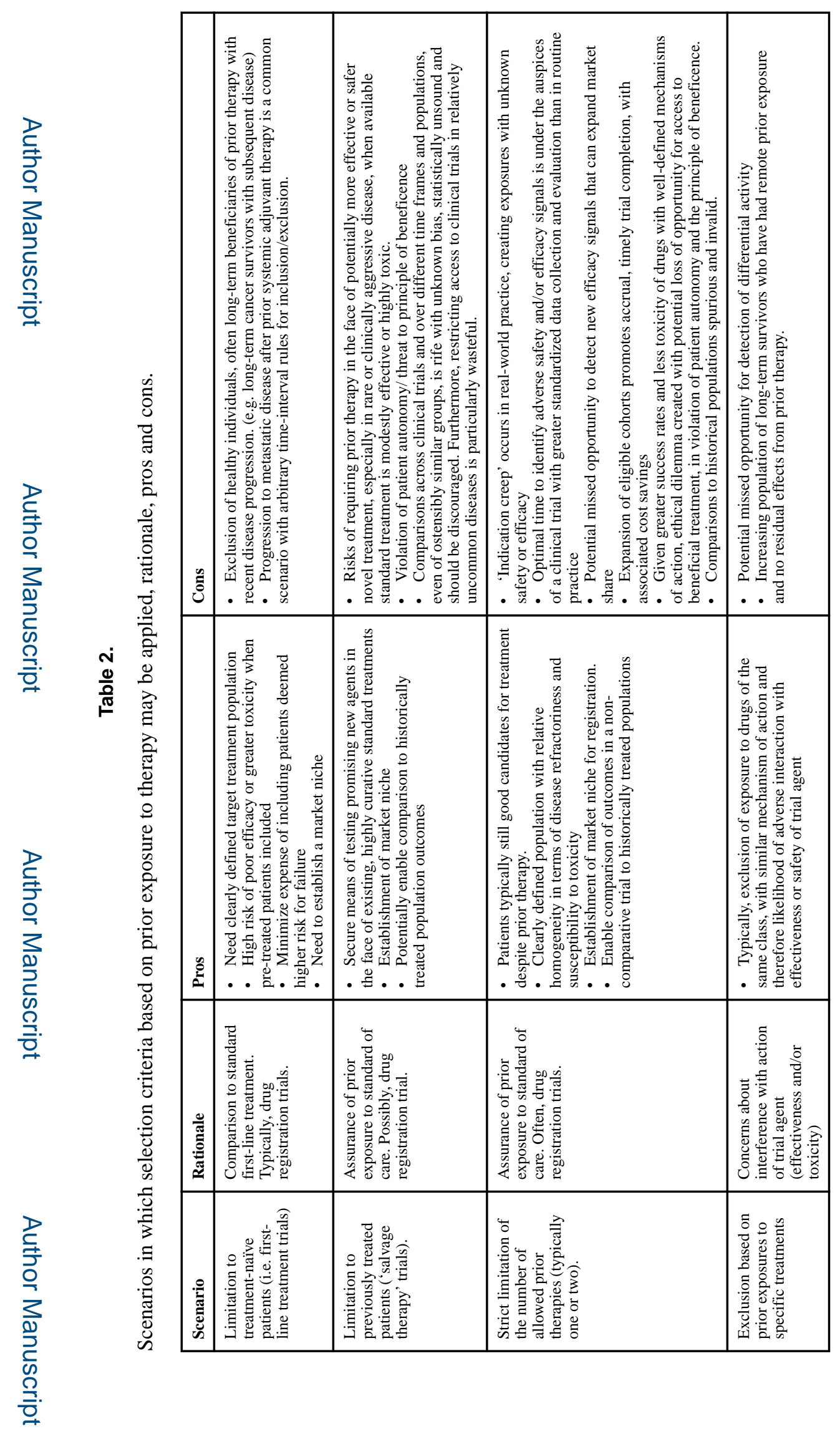

Clin Cancer Res. Author manuscript; available in PMC 2021 November 01. 